\title{
Waddling Gait \\ A complication of valproate therapy and a thought beyond vitamin D deficiency
}

Amit Sharma, "Siddhartha Sinha, Amit Narang, Dushyant K. Chouhan, Sumit Gupta

$$
\begin{aligned}
& \text { مشية متمايلة } \\
& \text { إحدى مضاعفات العلاج بدواء فالبوويت، وتصور مغاير بالنسبة لنقص فيتامين د }
\end{aligned}
$$

$$
\text { اميت شارما، سيدهاثا سيهنا، اميت نارانق، ديشونت كي. شاوهان، سوميت قويتا }
$$

ABSTRACT: Proximal muscle weakness is a common presentation in paediatric-orthopaedic clinics and is frequently paired with a vitamin D deficiency diagnosis. Recently, side effects of the extensive use of antiepileptic and antipsychotic drugs such as sodium valproate in childhood disorders are being documented. Sodium valproate causes a time-dependent, drug-induced proximal myopathy. We report a 13-year-old female patient who presented at the Orthopaedic Outpatient Department at Lady Hardinge Medical College, New Delhi, India, in 2019 with an abnormal gait. The patient was taking a combination therapy of sodium valproate, risperidone and trihexyphenidyl for absence seizures and a mood disorder. Following clinical investigations, the patient was diagnosed with proximal myopathy. As a result of elevated serum alkaline phosphatase and creatine kinase myocardial band levels, sodium valproate was replaced with ethosuximide and a carnitine supplementation was prescribed. The patient fully recovered and regained full mobility. Proximal myopathy had been incorrectly managed and assumed to be caused by a vitamin D deficiency.

Keywords: Muscle Weakness; Carnitine; Myopathy; Valproic Acid; Vitamin D Deficiency; Gait; Case Report; India.

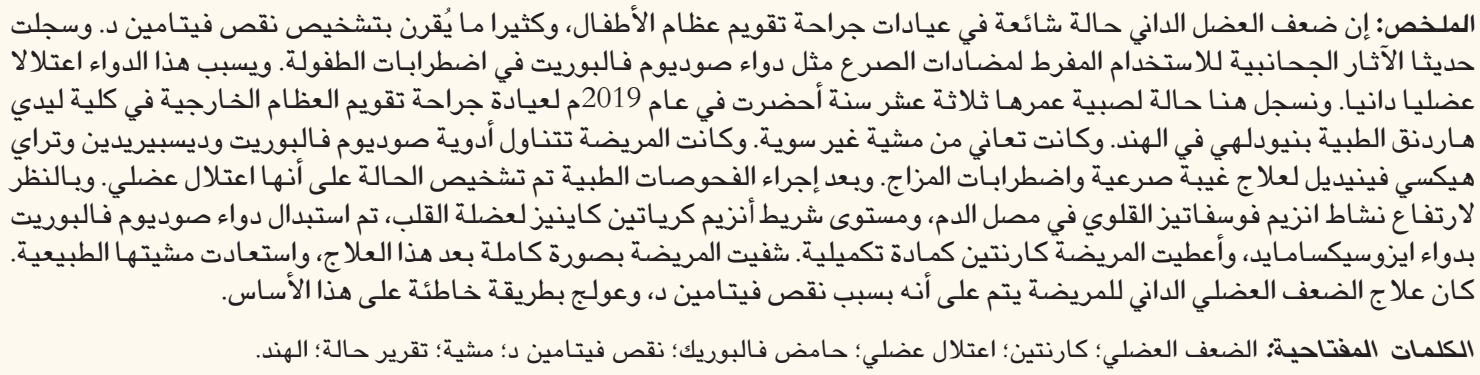

A BNORMAL GAIT IN CHILDREN, OFTEN NOTICED by parents or caregivers is a common presentation in orthopedic outpatient departments and requires a comprehensive work-up. Waddling gait in children is commonly caused by hip disorders such as developmental hip dysplasia, septic sequelae in the hip, bilateral Perthes disease and slipped capital femoral epiphysis. Some uncommon causes of waddling gait include myopathies due to endocrine disorders, drugs, systemic disorders and spinal muscular atrophy..$^{1-3}$ In developing countries, these cases are often attributed to the deficiency of vitamin D; empirical administration of vitamin $\mathrm{D}$ is usually given to the patient due to a lack of adequate resources for estimating vitamin D3 levels. While this strategy is useful in the majority of patients, some do not respond and the management of these patients therefore becomes a challenge.
Many drugs used in childhood disorders have the potential to cause a proximal myopathy. ${ }^{4}$ Sodium valproate is being extensively used for the management of epilepsy and mood disorders. Prolonged use of this drug may cause nausea, vomiting, anorexia, sedation, weight gain, alopecia, hepatotoxicity, encephalopathy and myopathy. ${ }^{5}$ Other antiepileptics/antipsychotics such as carbamazepine and oxcarbazepine do not cause myopathy. ${ }^{6}$ As many children present with signs and symptoms of proximal myopathy it is important to approach the case methodically and recognise druginduced myopathy. Following a detailed history and examination to determine non-response to empirical vitamin D supplementation, a diagnosis can be easily made. 


\section{Case Report}

A 13-year-old female patient presented to the Orthopaedic Outpatient Department, Lady Hardinge Medical College, New Delhi, India, in 2019 with an abnormal gait for the previous six months. Her mother noticed that she was finding it progressively more difficult to walk although there was no pain. There was no significant history of trauma, fever, night sweats, cough or diurnal variation in weakness. She was able to walk without support, go to school and carry out routine activities before the onset of symptoms. Over the prior six months she had felt tired after being physically active and developed a dull-aching pain in the hip and thighs that increased with prolonged activity and was relieved by rest and over-the-counter analgesics. The weakness progressively worsened to the extent that she was unable to walk to school, climb stairs or ride a bicycle. Her family members also noticed clumsiness in her gait which was associated with the weakness. The patient was managed by multiple practitioners with oral vitamin D supplementation but her gait did not improve. She was taking a combination of sodium valproate (200 mg, twice daily), risperidone (2 mg, once daily) and trihexyphenidyl ( $2 \mathrm{mg}$, once daily) for the past three years for absence seizures and a mood disorder which had been prescribed by a specialised institute. There was no history of excessive sleepiness, change in voice, weight gain or constipation. Pre-, peri- and postnatal histories were not significant and her developmental milestones were normal. There was no history of previous illness of a similar nature in the patient or in any family member.
On general physical examination, the patient was judged to be moderately built. She had no pallor, jaundice, oedema or lymphadenopathy. No neck swelling was noted and her skin and eyes appeared to be normal. The patient was walking with a waddling gait (Figure 1A-E) and an exaggerated lumbar lordosis. The power in hip abductors and deltoid was 4/5 and all other muscle groups had a power of $5 / 5$. Sensations were intact and all the deep tendon reflexes were normal and comparable bilaterally. The Trendelenburg test was bilaterally positive (Figure $1 \mathrm{~F}$ and $\mathrm{G}$ ). She was able to squat and sit cross-legged but had difficulty standing up. There was no weakness of the neck, chest and abdominal muscles. In addition, there was no calf hypertrophy and Gowers sign was negative.

Routine X-ray examination was normal and did not show any signs of rickets or any other hip disorders. Serum alkaline phosphatase was elevated to 897 international units (IU)/L (normal range: 53-128 IU/L) and serum creatine kinase myocardial band (CK-MB) was elevated to $35.9 \mathrm{IU} / \mathrm{L}$ (normal range: 0-25 IU/L). Serum vitamin D3 level was normal at $40.60 \mathrm{ng} / \mathrm{mL}$ (normal range: $30-50 \mathrm{ng} / \mathrm{mL}$ ) and thyroid function tests were within normal limits. She was continued with vitamin D supplementation with the expectation that time may improve the myopathy as she was already taking vitamin $\mathrm{D}$ supplementation.

At the one-week follow-up, the weakness had not improved. Serum alkaline phosphatase level was still elevated and the possibility this may be due to valproate was considered. Serum sodium valproate levels were tested and found to be within therapeutic levels. Nerve conduction studies and electromyography were
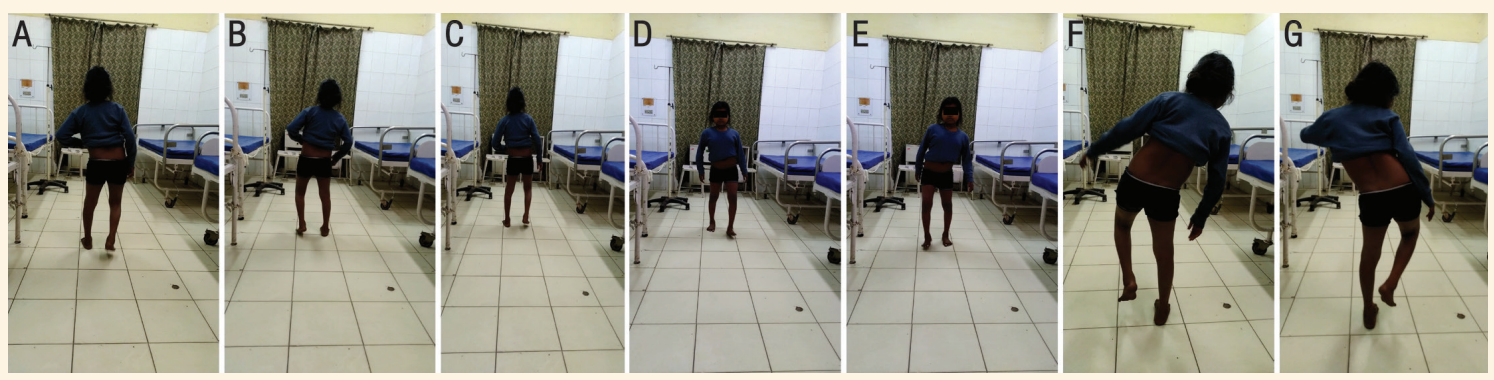

Figure 1: Photographs of a 13-year-old female patient showing her (A-E) gait at presentation and (F and G) the Trendelenburg test.
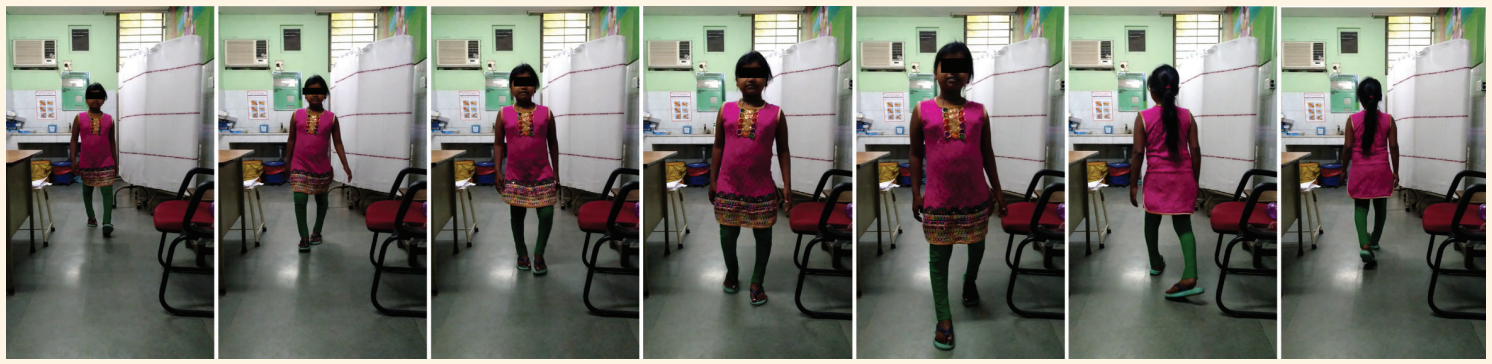

Figure 2: Photographs of a 13-year-old female patient showing an improved gait at three-month follow-up. 
essentially normal. Serum carnitine was not tested due to financial constraints.

Sodium valproate was stopped and carnitine supplementation was started. At the two-week followup, the patient showed signs of improvement. She was able to climb stairs and sit-up from a squatting position easily. However, the Trendelenburg test remained positive. At three-months follow-up, her gait had improved and the Trendelenburg test was negative. She reported being able to go to school, cycle and run without feeling pain or exhaustion [Figure 2]. Power in all muscle groups was 5/5 and serum alkaline phosphatase and CK-MB returned to normal levels. During this period, valproate was replaced by ethosuximide which did not cause recurrence of her psychiatric or musculoskeletal symptoms.

\section{Discussion}

When children with abnormal gait and weakness present to an orthopaedic outpatient department, many differential diagnoses should be considered. Proximal myopathy, which leads to an abnormal gait in children, may be caused by common drugs such as corticosteroids [Table 1]. ${ }^{4}$ Furthermore, endocrine and metabolic abnormalities such as thyroid and parathyroid dysfunction, malignancy and idiopathic inflammatory myopathies including polymyositis and dermatomyositis can cause proximal myopathy.

Table 1: Common drugs used in paediatric departments that cause myopathy ${ }^{4}$

$\begin{array}{lc}\text { Drug } & \text { Indication } \\ \begin{array}{l}\text { Anti-retroviral therapy } \\ \text { (e.g. zidovudine) } \\ \text { Glucocorticoid }\end{array} & \text { HIV } \\ \begin{array}{l}\text { Autoimmune disorders, asthma, } \\ \text { hormone replacement therapy and } \\ \text { nephrotic syndrome }\end{array} \\ \begin{array}{l}\text { Anti-malarial (e.g. chloro- } \\ \text { quine and hydroxy- } \\ \text { chloroquine) } \\ \text { Voriconazole } \\ \text { Phenytoin } \\ \text { Tretinoin }\end{array} \\ \text { Autoimmune disorders }\end{array}$

Congenital myopathies such as Duchenne and Becker muscular dystrophy also cause proximal myopathies. Infective causes such as HIV, influenza and hepatitis $\mathrm{B}$ and $\mathrm{C}$ should also be excluded from the differential diagnoses. ${ }^{3}$

Vitamin D deficiency has been reported to cause proximal myopathy and was found to be associated with increased serum alkaline phosphatase; this elevation can be caused by valproate toxicity. ${ }^{7-10}$ Myopathy due to vitamin $\mathrm{D}$ deficiency begins resolving within 4-6 weeks of treatment and completely resolves within six months and often shows skeletal changes unlike valproate-induced myopathy. ${ }^{11,12}$

Valproate-induced myopathy is not commonly suspected and there are very few reported cases on this condition; therefore, the exact incidence has not been calculated. A search via PubMed ${ }^{\circledR}$ (National Library of Medicine, Bethesda, Maryland, USA) and EMBASE (Elsevier, Amsterdam, Netherlands) revealed a total of three cases of valproate-induced myopathy [Table 2]. ${ }^{5,13,14}$ Children using sodium valproate present with signs of proximal myopathy with near normal routine biochemical parameters. ${ }^{5,13}$ Decreased serum carnitine levels due to valproate were first reported in 1982 by Ohtani et al. and later demonstrated in various other studies. ${ }^{7,15-19}$ Most antiepileptic drugs do not cause a decrease in serum carnitine level and myopathy has not been reported. ${ }^{6}$ Although no obvious pathological changes are seen in children using sodium valproate, the drug has a potential to cause cardiac dysfunction, encephalopathy, hepatotoxicity and cerebral oedema. ${ }^{13}$ An increase in serum alkaline phosphatase and creatine kinase induced by an antiepileptic drug may be confused with hypovitaminosis D.

Fatigue, difficulty in running, jumping, climbing stairs, difficulty in getting up from a sitting position and other signs of proximal muscle myopathy are common presentations in valproate-induced myopathy. Sensations and deep tendon reflexes are preserved. A waddling gait and exaggerated lumbar lordosis are also present. Needle electromyography may show signs of a myopathic pattern. ${ }^{13}$ Muscle biopsy shows ultrastructural abnorm-

Table 2: Biochemical parameters of various published case studies and the current case $\mathrm{e}^{5,13,14}$

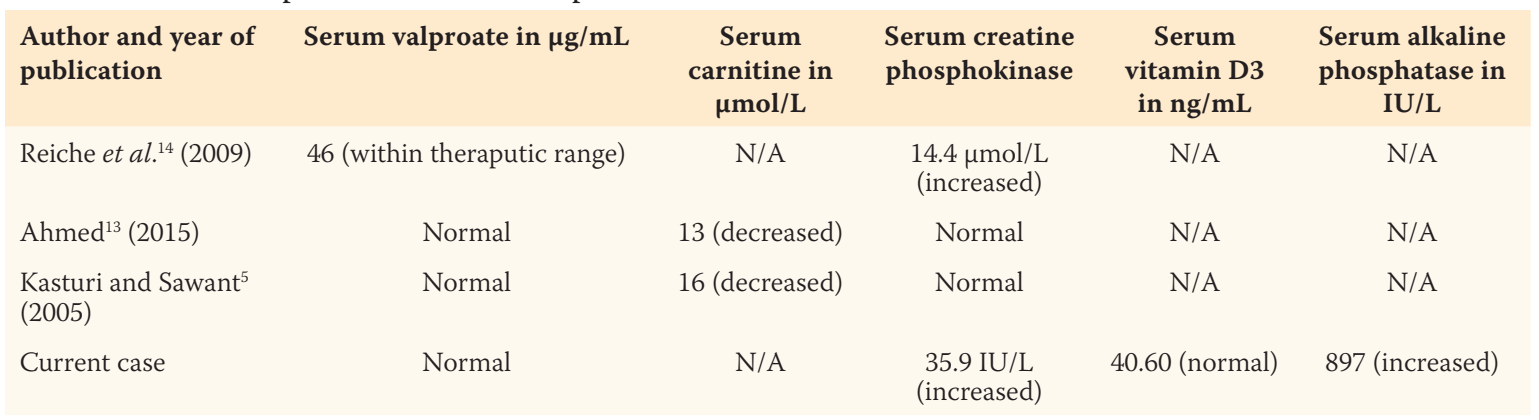


alities and electron microscopy shows lipid droplet accumulation in the muscles. ${ }^{16}$ Some authors stipulate that valproate-induced myopathy may be a timedependent, not dose-dependent, condition due to the progressive depletion of carnitine from muscle cells. ${ }^{5,7}$

Valproate causes a transient decrease in serum carnitine by increasing the renal clearance. Sodium valproate decreases alpha-ketoglutarate causing accumulation of toxic products. ${ }^{8}$ This accumulation of toxic byproducts and decreased level of serum carnitine, in addition to pre-existing risk factors, is the proposed pathogenesis for myopathic effects.

Risk factors exacerbating valproate-induced myopathy include young age, multiple neurological disabilities, poor nutrition, being underweight, multiple anticonvulsant drug therapy, hyperammonaemia and metabolic acidosis. Four months of valproate therapy can be considered as an adequate duration which can induce myopathy. Laub et al's study included 21 children on sodium valproate therapy for a duration of more than four months and found decreased levels of serum carnitine possibly due to alterations in the fatty acid metabolism because of the valproate. ${ }^{15}$

Discontinuing valproate with the addition of carnitine supplementation reverses the symptoms. Identifying children at risk and establishing a preventive dose of carnitine and prophylactic vitamin D supplementation for children on valproate therapy can further decrease the incidence of valproate-induced myopathy.

The current case was from a poor socio-economic background and had been taking multiple anticonvulsive medications due to absence seizures and a mood disorder. As a result, she developed myopathy which was unresponsive to empirical vitamin D supplementation based on clinical suspicion of rickets. After valproate was discontinued and carnitine supplementation was prescribed, the patient had a significant improvement in gait. It should be noted that there is a possibility that the patient had a mitochondrial cytopathy manifesting with seizures and mood changes, in whom valproate unmasked the myopathy as an additional manifestation of this underlying condition..$^{5,17}$ Limitations in diagnosis of the current case include a lack of serum vitamin $\mathrm{D}$ levels before empirical therapy was started and serum carnitine levels during the observation period. In this case, the clinical, laboratory and radiological parameters were strongly suggestive of proximal myopathy caused by sodium valproate. This diagnosis should be considered when encountering a patient with proximal myopathy who is unresponsive to vitamin D supplementation and on long-term anticonvulsive therapy.

\section{Conclusion}

Proximal myopathy in a developing country is commonly managed with vitamin D supplementation. However, if there is no response, other differential diagnoses should be considered beyond vitamin D deficiency. A detailed history and clinical examination with a focus on a past history of neurologic disease, extended duration of valproate intake and evaluation of proximal muscle power can aid in the diagnosis. Discontinuation of valproate and a combination of vitamin $\mathrm{D}$ and carnitine supplementation rapidly reverses proximal myopathy. Prophylactic supplementation of carnitine to prevent myopathy is currently still being evaluated.

\section{References}

1. Barkin RM, Barkin SZ, Barkin AZ. The limping child. J Emerg Med 2000; 18:331-9. https://doi.org/10.1016/s0736-4679(99) 00224-3.

2. Leung AK, Lemay JF. The limping child. J Pediatr Health Care 2004; 18:219-23. https://doi.org/10.1016/j.pedhc.2004.03.004.

3. Suresh E, Wimalaratna S. Proximal myopathy: Diagnostic approach and initial management. Postgrad Med J 2013; 89:470-7. https://doi.org/10.1136/postgradmedj-2013-131752.

4. Valiyil R, Christopher-Stine L. Drug-related myopathies of which the clinician should be aware. Curr Rheumatol Rep 2010; 12:213-20. https://doi.org/10.1007/s11926-010-0104-3.

5. Kasturi L, Sawant SP. Sodium valproate - Induced skeletal myopathy. Indian J Pediatr 2005; 72:243-4. https://doi.org/10.1007/ BF02859266.

6. Kurul S, Dirik E, Iscan A. Serum carnitine levels during oxcarbazepine and carbamazepine monotherapies in children with epilepsy. J Child Neurol 2003; 18:552-4. https://doi.org/10.1 177/08830738030180080201.

7. Coulter DL. Carnitine, valproate, and toxicity. J Child Neurol 1991; 6:7-14. https://doi.org/10.1177/088307389100600102.

8. Lheureux PE, Hantson P. Carnitine in the treatment of valproic acid-induced toxicity. Clin Toxicol (Phila) 2009; 47:101-11. https://doi.org/10.1080/15563650902752376

9. World Health Organization. Expert Committee on Medical Assessment of Nutritional Status [meeting held in Geneva from 21 to 27 August 1962]: report. From: https://apps.who.int/iris/ handle/10665/40561 Accessed: Oct 2019.

10. Reddy V, Srikantia SG. Serum alkaline phosphatase in malnourished children with rickets. J Pediatr 1967; 71:595-7. https://doi.org/10.1016/s0022-3476(67)80117-3.

11. Glerup H, Mikkelsen K, Poulsen L, Hass E, Overbeck S, Andersen $\mathrm{H}$, et al. Hypovitaminosis D myopathy without biochemical signs of osteomalacic bone involvement. Calcif Tissue Int 2000; 66:419-24. https://doi.org/10.1007/s002230010085.

12. Prabhala A, Garg R, Dandona P. Severe myopathy associated with vitamin D deficiency in western New York. Arch Intern Med 2000; 160:1199-203. https://doi.org/10.1001/archinte.160. 8.1199 .

13. Ahmed R. Sodium valproate-induced myopathy in a child. Sultan Qaboos Univ Med J 2015; 15:e146-7.

14. Reiche I, Tröger U, Postel SC, Wolf R, Bode-Böger SM. Valproic acid-induced myopathy in a patient with schizoaffective disorder. J Clin Psychopharmacol 2009; 29:402-3. https://doi.org/ 10.1097/JCP.0b013e3181ad2256. 
15. Laub MC, Paetzke-Brunner I, Jaeger G. Serum carnitine during valproic acid therapy. Epilepsia 1986; 27:559-62. https://doi. org/10.1111/j.1528-1157.1986.tb03584.x.

16. Shapira Y, Gutman A. Muscle carnitine deficiency in patients using valproic acid. J Pediatr 1991; 118:646-9. https://doi. org/10.1016/S0022-3476(05)83396-7.

17. Nanau RM, Neuman MG. Adverse drug reactions induced by valproic acid. Clin Biochem 2013; 46:1323-38. https://doi. org/10.1016/j.clinbiochem.2013.06.012.
18. Isenberg DA, Newham D, Edwards RH, Wiles CM, Young A. Muscle strength and pre-osteomalacia in vegetarian Asian women. Lancet 1982; 1:55. https://doi.org/10.1016/s0140-6736(82)92607-1.

19. Ohtani Y, Endo F, Matsuda I. Carnitine deficiency and hyperammonemia associated with valproic acid therapy. J Pediatr 1982; 101:782-5. https://doi.org/10.1016/s0022-3476(82)80320-x. 